\title{
Examining the Reaction Times of International Level Badminton Players Under 15
}

\author{
Mehmet Fatih Yüksel ${ }^{1, *(D)}$ and Gülsen Tosun Tunç ${ }^{2}$ \\ 1 Faculty of Education, Necmettin Erbakan University, Konya 42090, Turkey \\ 2 Faculty of Sports Science, Aksaray University, Aksaray 68100, Turkey; gulsentit@hotmail.com \\ * Correspondence: yukselmehmetfatih@gmail.com; Tel.: +90-505-391-1739
}

Received: 23 January 2018; Accepted: 2 March 2018; Published: 5 March 2018

\begin{abstract}
This research was conducted to examine the simple visual and auditory reaction times of badminton players of the national teams and to examine the possible effects of reaction-time average values of badminton players under the age of 15 who participated in the fifth International Rumi Child Sport Games. In total, 48 players $($ male $=24$; female $=24)$ from six countries (Turkey, Azerbaijan, Bulgaria, Macedonia, Serbia, Georgia) participated in the study. Stature, bodyweight, BMI, dominant and non-dominant hand visual and auditory reaction time values of the participants were detected. At the end of the study, it was determined that there were statistically significant differences between the countries in terms of male dominant and non-dominant hand visual reaction values, and male dominant hand auditory reaction values. It was also determined that there were statistically significant differences between the countries in terms of female bodyweight, BMI, dominant and non-dominant hand visual reaction values, and female non-dominant hand auditory reaction values. There was statistically significant difference between female and male players with regards to dominant and non-dominant hand visual, and non-dominant hand auditory reaction values. In conclusion, it was determined that the reaction times of the top ranking countries in the fifth International Rumi Child Sport Games under- 15 were at a better level, and it can be concluded that this factor played an important role for success alongside with technique and tactic features.
\end{abstract}

Keywords: badminton; under 15; reaction time

\section{Introduction}

Badminton is a racquet sport in which leaps, veers, and quick arm movements are needed [1]. The sport is played by two or four people without physical contact on a rectangle court divided into two equal areas by a net [2]. Badminton is a rapidly developing sport worldwide. There are 188 member countries in the International Badminton Federation, and there are 111 million licensed players around the world [3].

Literature review research indicates that the shuttlecock bounces back $0.93 \mathrm{~s}$ after a shot in a rally [4], and that the average time of a rally is in between 6-11.5 s [5,6]. Another study reported that the longest rally times in females and males consecutively were 34.6 and $38.4 \mathrm{~s}$ [7]. A different study emphasized that the time of intervals between the points were 27-30 s [8]. Additionally, another study stated that the maximal speed of a shuttlecock was measured as $421 \mathrm{~km} / \mathrm{h}$ and that it was the fastest ball in the world $[9,10]$. In another research study, Seth [11] indicated that badminton play was characterized as short period, high intensity, and short intervals. Moreover, coordinative talents are vital in badminton sport. One of these coordinative features is reaction, which is important for responding fast. Particularly the high speed of the shuttlecock leaves too little a time to react, thus, badminton player should quickly and accurately decide during the game. In brief, the fast return of the shuttlecock in less than one second necessitates quick thinking and reacting to the stimulus during the game. 
When the literature was examined, although there were many research studies, which examined the reaction times of the badminton players and stated that they had better reaction times compared to control groups [9,12-17], the reaction times of under-15 international level players were not observed. That is why it is evaluated vital to examine the reaction times of the under-15 international badminton players for a contribution to the field.

The purpose of this study was to examine simple visual and auditory reaction times of under-15 badminton players from different countries who participated in the fifth International Rumi Child Sport Games. A secondary purpose was to examine the possible effects of reaction times on tournament results.

\section{Materials and Methods}

\subsection{Participants}

The study was conducted on players of under-15 national teams from 6 countries (Turkey, Azerbaijan, Bulgaria, Macedonia, Serbia, Georgia) who participated in the 5th International Rumi Child Sport Games. Since the six national teams who participated in the tournament were composed of 4 female and 4 male players, 48 players in total participated in the study. This study was conducted according to the Helsinki Declaration.

\subsection{Place and Time of Measurement}

The measurements were taken a day before the game between 10:00 and 12:00 a.m. The measurements were conducted in a room in the sport hall, which was insulated against sound and noise, with moderate light intensity, and cleared of the materials that could disturb the concentration of the players.

\subsection{Procedures}

All participants signed an informed consent form. Permission was gained from the tournament organization committee and the team managers.

In defining the ages of the players, identification and passport information was based on. The stature, body weight, and simple visual-auditory values of the players were recorded after tests and measurements, body mass index (BMI) was calculated by means of the formula.

After the stature and body weight measurements, 15 min of warm-up period was given to the players before the reaction time test. Necessary information about the tests was explained to the players before the applications. They were shown the applications of the tests. They were repeatedly informed about the objective and importance of the research study, thus their motivation and ambition was to be increased. The players participated in the measurements and tests wearing sportswear.

The dominant hands of the players were determined based on the question "With which hand do you hold the racket?"

Height and Body weight: In the linear measurements a tapeline with $0.01 \mathrm{~m}$ sensitivity score was used. Weight measurements were made with a digital weighing scale with a sensitivity level of $0.01 \mathrm{~kg}$. The measurements were made twice and the average was taken [18].

Body mass index; using body weights and lengths, BMI was determined using the BMI = Body weight/(Stature in meters) $)^{2}$ formula.

Visual-auditory reaction times measurement: visual and auditory reaction times were located via New-Test 2000 measurement device. The device is composed of two parts. The first part is the button that the subject presses with the finger against audible (voice) or visual (light) stimulus. The second part is used by the tester. It manages the type (visual or auditory) and number of the stimuli that are sent to the subject. The subject and the tester sit face to face on a table, and the tester conducts the test.

The subject is in a sitting position, one hand is on the table in front of the device that emits audible or light stimulus, while the other hand is let free without taking support from anything. In auditory 
reaction test, the tester gives the test start warning when the subject is ready. From that moment on, an auditory stimulus ("beep" sound) is heard within randomized periods. Hearing the stimulus, the subject presses the button on the device as fast as possible and stops the sound stimulus. In the visual reaction test, the button on the device flashes a light, and the subject presses the button as fast as possible to turn off the light stimulus. The time span between the stimulus and the reaction is called as the reaction time. The subject repeated the measurements for 10 times. The first 5 of them were accepted as exercise, and the average of the last 5 repeats was accepted as the reaction time, and recorded in ms [18].

\subsection{Statistical Analysis}

SPSS 24.0 (IBM Corp., Armonk, NY, USA) program was used in the analysis of the data obtained through the research. Arithmetic averages and standard deviations were given by descriptive statistics. Considering the number of the participant players, Kruskal-Wallis analysis (one of non-parametric tests) was used in order to define whether there was a significant difference between countries regarding parameters. If there was a significant difference, Kruskal-Wallis analysis was also used to locate the countries with significant difference. Mann-Whitney $U$ analysis was used in order to examine whether there was a statistically significant difference in the reaction-time parameter with regards to gender. Significance level was admitted as $p<0.05$.

\section{Results}

Table 1 shows the age, height, body weight, BMI and simple visual and auditory reaction time average values of country athletes participating in the study.

When Table 2 is examined, according to the Kruskal-Wallis analysis results, it was defined that there was statistically significant differences $(p<0.05)$ between;

a. Bulgarian players and Macedonian players for bodyweight,

b. Bulgarian players and Turkish/Serbian players for BMI,

c. Turkish and Bulgarian players for dominant hand visual reactions,

d. Turkish players and Bulgarian players for non-dominant hand visual reactions,

e. Serbian players and Bulgarian/Azeri players for non-dominant hand visual reactions,

f. Turkish/Serbian/Macedonian players and Bulgarian players for non-dominant hand auditory reactions,

g. Serbian players and Azeri players for non-dominant hand auditory reactions.

There was no statistically significant difference between the countries in terms of age, stature, and dominant hand auditory reaction parameters according to the Kruskal-Wallis Analysis results $(p>0.05)$.

When Table 3 is examined, according to the Kruskal-Wallis Analysis results, it was defined that there was statistically significant differences $(p<0.05)$ between;

a. Serbian players and Bulgarian players for dominant hand visual reactions,

b. Turkish/Serbian players and Bulgarian players for non-dominant hand visual reactions,

c. Serbian players and Bulgarian players for dominant hand auditory reactions.

There was no statistically significant difference between the countries in terms of age, stature, bodyweight, BMI, and non-dominant hand auditory reaction parameters according to the Kruskal-Wallis analysis results $(p>0.05)$.

When Table 4 is examined, it was defined that there was a statistically significant difference $(p<0.05)$ between female and male groups with regards to three parameters. Firstly, dominant hand visual reactions $(U=164.000, p<0.05)$, secondly, non-dominant hand visual reactions $(U=137.000$, $p<0.05)$, and thirdly, non-dominant hand auditory reactions $(U=107.500, p<0.05)$ parameters. 
Table 1. The average values of age, height, weight, BMI and basic reaction times of the athletes.

\begin{tabular}{ccccccccc}
\hline Parameters & Gender & $\boldsymbol{n}$ & TURKEY & AZERBAIJAN & BULGARIA & MACEDONIA & SERBIA & GEORGIA \\
\hline \multirow{2}{*}{ Age } & $\mathrm{F}$ & 4 & $14.40 \pm 0.29$ & $14.68 \pm 0.22$ & $14.58 \pm 0.26$ & $14.2 \pm 0.43$ & $14.43 \pm 0.28$ & $14.43 \pm 0.38$ \\
& $\mathrm{M}$ & 4 & $14.50 \pm 0.22$ & $14.33 \pm 0.30$ & $14.48 \pm 0.40$ & $14.28 \pm 0.33$ & $14.43 \pm 0.30$ & $14.30 \pm 0.22$ \\
\hline \multirow{2}{*}{ Height } & $\mathrm{F}$ & 4 & $171.0 \pm 5.35$ & $165.75 \pm 3.50$ & $165.75 \pm 5.97$ & $160.0 \pm 6.38$ & $167.25 \pm 7.63$ & $167.75 \pm 4.03$ \\
& $\mathrm{M}$ & 4 & $175.25 \pm 2.50$ & $167.25 \pm 5.62$ & $167.25 \pm 8.85$ & $169.0 \pm 5.48$ & $170.0 \pm 3.56$ & $167.50 \pm 2.50$ \\
\hline \multirow{2}{*}{ Weight } & $\mathrm{F}$ & 4 & $52.25 \pm 7.59$ & $55.90 \pm 4.44$ & $61.75 \pm 4.65$ & $49.63 \pm 2.06$ & $51.25 \pm 4.65$ & $54.50 \pm 3.98$ \\
& $\mathrm{M}$ & 4 & $61.25 \pm 2.75$ & $58.38 \pm 4.04$ & $56.75 \pm 7.18$ & $63.50 \pm 5.0$ & $55.25 \pm 2.50$ & $61.33 \pm 3.62$ \\
\hline \multirow{2}{*}{ BMI } & $\mathrm{F}$ & 4 & $17.81 \pm 1.93$ & $20.33 \pm 1.07$ & $22.47 \pm 1.12$ & $19.41 \pm 0.86$ & $18.35 \pm 1.72$ & $19.87 \pm 1.78$ \\
& $\mathrm{M}$ & 4 & $19.96 \pm 1.21$ & $20.87 \pm 1.16$ & $20.23 \pm 1.11$ & $22.26 \pm 1.85$ & $19.16 \pm 1.54$ & $21.85 \pm 0.88$ \\
\hline Visual reaction & $\mathrm{F}$ & 4 & $230.25 \pm 8.38$ & $309.75 \pm 25.89$ & $326.75 \pm 20.11$ & $294.75 \pm 20.32$ & $261.75 \pm 29.02$ & $303.75 \pm 20.89$ \\
dominant hand & $\mathrm{M}$ & 4 & $228.25 \pm 13.87$ & $284.50 \pm 33.93$ & $300.50 \pm 35.52$ & $268.0 \pm 25.81$ & $224.0 \pm 23.93$ & $276.75 \pm 25.83$ \\
\hline Visual reaction & $\mathrm{F}$ & 4 & $320.25 \pm 14.57$ & $354.75 \pm 9.74$ & $356.0 \pm 6.16$ & $340.0 \pm 9.42$ & $306.0 \pm 27.26$ & $342.50 \pm 9.26$ \\
non-dominant hand & $\mathrm{M}$ & 4 & $293.50 \pm 11.09$ & $323.0 \pm 12.25$ & $352.0 \pm 10.86$ & $312.0 \pm 11.86$ & $271.25 \pm 21.38$ & $320.0 \pm 7.48$ \\
\hline Auditory reaction & $\mathrm{F}$ & 4 & $296.75 \pm 20.11$ & $317.25 \pm 23.54$ & $319.75 \pm 18.63$ & $307.50 \pm 20.24$ & $287.0 \pm 23.74$ & $319.50 \pm 18.81$ \\
dominant hand & $\mathrm{M}$ & 4 & $271.0 \pm 28.72$ & $314.25 \pm 24.87$ & $329.25 \pm 16.60$ & $299.0 \pm 20.94$ & $260.50 \pm 33.32$ & $312.50 \pm 17.71$ \\
\hline Auditory reaction & $\mathrm{F}$ & 4 & $312.25 \pm 20.32$ & $338.0 \pm 17.57$ & $347.25 \pm 18.61$ & $321.0 \pm 11.63$ & $305.50 \pm 23.02$ & $330.25 \pm 9.67$ \\
non-dominant hand & $\mathrm{M}$ & 4 & $286.50 \pm 23.45$ & $309.75 \pm 21.20$ & $316.50 \pm 21.46$ & $300.25 \pm 13.30$ & $282.50 \pm 26.94$ & $307.50 \pm 11.68$ \\
\hline
\end{tabular}


Table 2. The Kruskal-Wallis analysis results of the female badminton players based on countries.

\begin{tabular}{|c|c|c|c|c|c|c|}
\hline Parameters & Country & $n$ & Mean Rank & $\mathrm{df}$ & $p$ & Difference \\
\hline \multirow{7}{*}{ Age } & TURKEY (T) & 4 & 11.00 & \multirow{7}{*}{5} & \multirow{7}{*}{0.468} & \\
\hline & AZERBAIJAN (A) & 4 & 17.50 & & & \\
\hline & BULGARIA (B) & 4 & 15.13 & & & \\
\hline & MACEDONIA (M) & 4 & 7.88 & & & \\
\hline & SERBIA (S) & 4 & 11.63 & & & \\
\hline & GEORGIA (G) & 4 & 11.88 & & & \\
\hline & Total & 24 & & & & \\
\hline \multirow{7}{*}{ Height } & TURKEY (T) & 4 & 18.63 & \multirow{7}{*}{5} & \multirow{7}{*}{0.245} & \multirow{7}{*}{-} \\
\hline & AZERBAIJAN (A) & 4 & 11.63 & & & \\
\hline & BULGARIA (B) & 4 & 12.75 & & & \\
\hline & MACEDONIA (M) & 4 & 6.00 & & & \\
\hline & SERBIA (S) & 4 & 14.00 & & & \\
\hline & GEORGIA (G) & 4 & 12.00 & & & \\
\hline & Total & 24 & & & & \\
\hline \multirow{7}{*}{ Weight } & TURKEY (T) & 4 & 11.38 & \multirow{7}{*}{5} & \multirow{7}{*}{$0.041 *$} & \multirow{7}{*}{$\mathrm{M}<\mathrm{B}$} \\
\hline & AZERBAIJAN (A) & 4 & 15.38 & & & \\
\hline & BULGARIA (B) & 4 & 20.88 & & & \\
\hline & MACEDONIA (M) & 4 & 5.25 & & & \\
\hline & SERBIA (S) & 4 & 9.00 & & & \\
\hline & GEORGIA (G) & 4 & 13.13 & & & \\
\hline & Total & 24 & & & & \\
\hline \multirow{7}{*}{ BMI } & TURKEY (T) & 4 & 6.00 & \multirow{7}{*}{5} & \multirow{7}{*}{$0.021 *$} & \multirow{7}{*}{$\begin{array}{l}\mathrm{T}<\mathrm{B} \\
\mathrm{S}<\mathrm{B}\end{array}$} \\
\hline & AZERBAIJAN (A) & 4 & 14.75 & & & \\
\hline & BULGARIA (B) & 4 & 22.00 & & & \\
\hline & MACEDONIA (M) & 4 & 11.75 & & & \\
\hline & SERBIA (S) & 4 & 7.25 & & & \\
\hline & GEORGIA (G) & 4 & 13.25 & & & \\
\hline & Total & 24 & & & & \\
\hline \multirow{7}{*}{$\begin{array}{l}\text { Visual reaction } \\
\text { dominant hand }\end{array}$} & TURKEY (T) & 4 & 3.25 & \multirow{7}{*}{5} & & \\
\hline & AZERBAIJAN (A) & 4 & 16.63 & & & \\
\hline & BULGARIA (B) & 4 & 19.75 & & & \\
\hline & MACEDONIA (M) & 4 & 13.00 & & $0.010 *$ & $\mathrm{~T}<\mathrm{B}$ \\
\hline & SERBIA (S) & 4 & 7.25 & & & \\
\hline & GEORGIA (G) & 4 & 15.13 & & & \\
\hline & Total & 24 & & & & \\
\hline & TURKEY $(\mathrm{T})$ & 4 & 5.75 & & & \\
\hline & AZERBAIJAN (A) & 4 & 19.25 & & & \\
\hline & BULGARIA (B) & 4 & 20.50 & & & $\mathrm{~T}<\mathrm{B}$ \\
\hline Visual reaction & MACEDONIA (M) & 4 & 11.63 & 5 & $0.003 *$ & $\mathrm{~S}<\mathrm{B}$ \\
\hline & SERBIA (S) & 4 & 4.25 & & & $\mathrm{~S}<\mathrm{A}$ \\
\hline & GEORGIA (G) & 4 & 13.63 & & & \\
\hline & Total & 24 & & & & \\
\hline & TURKEY (T) & 4 & 9.38 & & & \\
\hline & AZERBAIJAN (A) & 4 & 14.75 & & & \\
\hline & BULGARIA (B) & 4 & 16.13 & & & \\
\hline Auditory reaction & MACEDONIA (M) & 4 & 11.00 & 5 & 0.297 & - \\
\hline & SERBIA (S) & 4 & 7.13 & & & \\
\hline & GEORGIA (G) & 4 & 16.63 & & & \\
\hline & Total & 24 & & & & \\
\hline & TURKEY (T) & 4 & 8.25 & & & \\
\hline & AZERBAIJAN (A) & 4 & 16.50 & & & $\mathrm{~T}<\mathrm{B}$ \\
\hline & BULGARIA (B) & 4 & 19.75 & & & $\mathrm{~S}<\mathrm{B}$ \\
\hline Auditory reaction & MACEDONIA (M) & 4 & 9.88 & 5 & $0.044 *$ & $M<B$ \\
\hline non-dominant hand & SERBIA (S) & 4 & 5.88 & & & $\mathrm{~S}<\mathrm{A}$ \\
\hline & GEORGIA (G) & 4 & 14.75 & & & \\
\hline & Total & 24 & & & & \\
\hline
\end{tabular}


Table 3. The Kruskal-Wallis analysis results of the male badminton players based on countries.

\begin{tabular}{|c|c|c|c|c|c|c|}
\hline Parameters & Country & $n$ & Mean Rank & $\mathrm{df}$ & $p$ & Difference \\
\hline \multirow{7}{*}{ Age } & TURKEY (T) & 4 & 15.50 & \multirow{7}{*}{5} & \multirow{7}{*}{0.812} & \multirow{7}{*}{-} \\
\hline & AZERBAIJAN (A) & 4 & 11.13 & & & \\
\hline & BULGARIA (B) & 4 & 14.63 & & & \\
\hline & MACEDONIA (M) & 4 & 9.75 & & & \\
\hline & SERBIA (S) & 4 & 13.50 & & & \\
\hline & GEORGIA (G) & 4 & 10.50 & & & \\
\hline & Total & 24 & & & & \\
\hline \multirow{7}{*}{ Height } & TURKEY (T) & 4 & 20.75 & \multirow{7}{*}{5} & \multirow{7}{*}{0.165} & \multirow{7}{*}{-} \\
\hline & AZERBAIJAN (A) & 4 & 9.75 & & & \\
\hline & BULGARIA (B) & 4 & 11.13 & & & \\
\hline & MACEDONIA (M) & 4 & 12.38 & & & \\
\hline & SERBIA (S) & 4 & 12.88 & & & \\
\hline & GEORGIA (G) & 4 & 8.13 & & & \\
\hline & Total & 24 & & & & \\
\hline \multirow{7}{*}{ Weight } & TURKEY (T) & 4 & 15.88 & \multirow{7}{*}{5} & \multirow{7}{*}{0.128} & \multirow{7}{*}{-} \\
\hline & AZERBAIJAN (A) & 4 & 11.63 & & & \\
\hline & BULGARIA (B) & 4 & 9.13 & & & \\
\hline & MACEDONIA (M) & 4 & 17.50 & & & \\
\hline & SERBIA (S) & 4 & 5.50 & & & \\
\hline & GEORGIA (G) & 4 & 15.38 & & & \\
\hline & Total & 24 & & & & \\
\hline \multirow{7}{*}{ BMI } & TURKEY (T) & 4 & 9.50 & \multirow{7}{*}{5} & \multirow{7}{*}{0.056} & \multirow{7}{*}{-} \\
\hline & AZERBAIJAN (A) & 4 & 12.75 & & & \\
\hline & BULGARIA (B) & 4 & 10.13 & & & \\
\hline & MACEDONIA (M) & 4 & 18.00 & & & \\
\hline & SERBIA (S) & 4 & 5.63 & & & \\
\hline & GEORGIA (G) & 4 & 19.00 & & & \\
\hline & Total & 24 & & & & \\
\hline \multirow{7}{*}{$\begin{array}{l}\text { Visual reaction } \\
\text { dominant hand }\end{array}$} & TURKEY (T) & 4 & 6.13 & & & \\
\hline & AZERBAIJAN (A) & 4 & 16.50 & & & \\
\hline & BULGARIA (B) & 4 & 19.75 & & & \\
\hline & MACEDONIA (M) & 4 & 12.50 & 5 & $0.017 *$ & $\mathrm{~S}<\mathrm{B}$ \\
\hline & SERBIA (S) & 4 & 5.00 & & & $\mathrm{~T}<\mathrm{B}$ \\
\hline & GEORGIA (G) & 4 & 15.13 & & & \\
\hline & Total & 24 & & & & \\
\hline & TURKEY (T) & 4 & 6.25 & & & \\
\hline & AZERBAIJAN (A) & 4 & 15.88 & & & \\
\hline & BULGARIA (B) & 4 & 22.38 & & & \\
\hline Visual reaction & MACEDONIA (M) & 4 & 12.00 & 5 & $0.002 *$ & $\mathrm{~T}<\mathrm{B}$ \\
\hline & SERBIA (S) & 4 & 3.25 & & & $\mathrm{~S}<\mathrm{B}$ \\
\hline & GEORGIA (G) & 4 & 15.25 & & & \\
\hline & Total & 24 & & & & \\
\hline & TURKEY (T) & 4 & 6.50 & & & \\
\hline & AZERBAIJAN (A) & 4 & 16.13 & & & \\
\hline & BULGARIA (B) & 4 & 19.75 & & & \\
\hline Auditory reaction & MACEDONIA (M) & 4 & 12.13 & 5 & $0.017^{*}$ & $\mathrm{~S}<\mathrm{B}$ \\
\hline & SERBIA (S) & 4 & 4.75 & & & \\
\hline & GEORGIA (G) & 4 & 15.75 & & & \\
\hline & Total & 24 & & & & \\
\hline & TURKEY (T) & 4 & 9.63 & & & \\
\hline & AZERBAIJAN (A) & 4 & 14.63 & & & \\
\hline & BULGARIA (B) & 4 & 16.88 & & & \\
\hline Auditory reaction & MACEDONIA (M) & 4 & 11.50 & 5 & 0.439 & - \\
\hline non-dominant hand & SERBIA (S) & 4 & 7.75 & & & \\
\hline & GEORGIA (G) & 4 & 14.63 & & & \\
\hline & Total & 24 & & & & \\
\hline
\end{tabular}


Table 4. The averages of reaction times and Mann-Whitney U analysis results of the female and male badminton players.

\begin{tabular}{|c|c|c|c|c|c|c|c|}
\hline Parameters & Gender & $n$ & Mean & Std. Deviation & Mean Rank & $\mathbf{U}$ & $p$ \\
\hline \multirow{2}{*}{ Visual reaction dominant hand } & $\mathrm{F}$ & 24 & 287.83 & 38.27 & 19.33 & \multirow[b]{2}{*}{164.000} & \multirow[b]{2}{*}{$0.011 *$} \\
\hline & M & 24 & 263.67 & 37.74 & 29.67 & & \\
\hline \multirow[b]{2}{*}{ Visual reaction non-dominant hand } & $\mathrm{F}$ & 24 & 336.58 & 22.47 & 18.21 & \multirow[b]{2}{*}{137.000} & \multirow{2}{*}{$0.002 *$} \\
\hline & M & 24 & 311.96 & 28.20 & 30.79 & & \\
\hline \multirow{2}{*}{ Auditory reaction dominant hand } & $\mathrm{F}$ & 24 & 307.96 & 22.45 & 22.33 & \multirow{2}{*}{236.000} & \multirow{2}{*}{0.283} \\
\hline & M & 24 & 297.75 & 33.03 & 26.67 & & \\
\hline \multirow{2}{*}{ Auditory reaction non-dominant hand } & $\mathrm{F}$ & 24 & 325.71 & 21.34 & 16.98 & \multirow{2}{*}{107.500} & \multirow{2}{*}{0.000 * } \\
\hline & M & 24 & 300.50 & 22.01 & 32.02 & & \\
\hline
\end{tabular}

\section{Discussion and Conclusions}

In our research, we aimed to examine the simple visual and auditory reaction times of under-15 badminton players of Turkey, Azerbaijan, Bulgaria, Macedonia, Serbia, and Georgia national teams which participated in the fifth International Rumi Child Sport Games.

There was no statistically significant difference between the countries in terms of average age, and stature parameters of the female and male groups. Considering the height of the badminton net from the ground $(152-155 \mathrm{~cm})$, it can be stated that all of the players participating in the research were far taller than the height of the net, so net height did not affect success. The fact that the height of the subject group in the research was higher than the net was supported by numerous similar studies regarding the height of the badminton players and net height $[1,9,15,19-24]$.

There was no statistically significant difference between the countries in terms of body weight, and BMI parameters of the male groups $(p>0.05)$. In the country comparison of female badminton players, there were statistically significant differences $(p<0.05)$ between Serbia and Bulgaria for bodyweight. There was also statistically significant difference among Turkish/Serbian and Bulgarian players' BMI. Body weight has a vital role in badminton, since it requires the body to leap up numerous times from the ground despite gravity. Accordingly, it can be stated that Bulgarian female players' BMI values were higher than the average, which created a disadvantage. Also, the BMI findings of all the groups were within the normal limits stated by the World Health Organization [25].

When the visual and auditory reaction time results of the female and male players participating in the research were examined, Turkey and Serbia had the lowest (best) values for both dominant and non-dominant hand. Moreover, it was observed that male players compared to females, and dominant hand compared to non-dominant hand had lower (better) values. According to research conducted in India, the visual times of the control group, which was formed by male badminton players and healthy individuals, were respectively $283.46 \mathrm{~ms}$ and $347.76 \mathrm{~ms}$. There was statistically significant difference in favor of the badminton players [13]. Remarkable improvement was observed in the visual time values of the badminton players who underwent six-week exercises [14]. According to another research conducted in Iran, the visual reaction values of the male badminton players in dominant and non-dominant hands respectively were determined as $130.46 \mathrm{~ms}$ and $131.27 \mathrm{~ms}$ [16]. Similarly, in another research study on under- 15 male badminton players, it was reported that the visual reaction time was $0.27 \mathrm{~s}$ [26]. In a study in Poland on the national badminton players who were visually and aurally stimulated, dominant and non-dominant hand reaction time values were respectively determined as $0.26 \mathrm{~s}$ and $0.27 \mathrm{~s}$ [9]. Existing literature findings, except the Dube et al. [16] study, are generally supporting our research.

In research studies on different sport branches (Football, Handball, Volleyball, Wrestling, Ice-skating), simple visual and auditory reaction time average values were reported to be in between 355-405 ms [27-29]. However, it was observed that the reaction time average values of this study were better compared to the abovementioned other sport branches. This might be because the reaction time improving exercises were conducted more in badminton sports branch. Additionally, that the 
badminton players have better reaction times might be explained with the result of long years' training with racquet. In another study on national badminton players under-17, the results of visual and auditory reaction time values were similar to our research while auditory reaction time values were (better) lower [15]. Similarly, in a research on international players by Revan et al. [12], the auditory reaction values reported were lower compared to visual reaction values. On the other hand, different from above mentioned studies, in our study, it was observed that the visual reaction values of both female and male players in both hands were lower (better) compared to auditory values. This may be because of the variables at the measuring moment. Moreover, that the visual reaction times are more improved compared to auditory reactions is an expected situation for the players who exercised for years reacting to visual stimulus, which is the main characteristic of the badminton game, and this situation is supported with the data obtained.

A player may need to practice for hours, days, or even months to improve oneself. As a result of the developments in training science, it is known that the quality of different exercise methods have been increased and therefore it is reflected on physical performance. It can be accepted as the strength of the study that all of the data obtained from the research was from the international level badminton players with a full participation. Yet, it is considered that further research studies, similar to this narrow-scoped study, should be conducted on different age categories and with broader participation. Thus, the findings of this research will be ascertained whether they are replicable in other samples or cohorts of badminton players.

In this research, visual and auditory reaction times of badminton players of the national teams under 15, who participated in the fifth International Rumi Child Sport Games from different countries, were examined. Having the lowest (best) reaction time values in both males and females, Turkish and Serbian national teams ranked in the first three in the tournament. During the game it is vital for the players to have a good level of reaction time against heavy hits like smash, drive, and net-kill. We consider that reaction time is an important feature particularly for the badminton players as it is important for many other sports branch. The players of the ranking first three countries having better reaction times supported this determination. Therefore, it can be clearly concluded that the reaction time plays an important role for success.

We evaluate that it is a necessity for the training programs to include reaction time improving exercises considering the characteristic features of badminton such as fast speed of shuttlecock and the stimulus being continuously visual. Thus, it can be stated that the reaction time of the players will improve and it will contribute to the game performance. It is suggested for the trainers/sports scientists to include exercises such as Standing Ball Drop, Ball Drop and Sprint, Kneeling Ball Catch which involve particularly visual stimuli.

Acknowledgments: The authors sincerely thank the subjects who participated in this study and made this project possible. This research received no funding.

Author Contributions: The leading author Mehmet Fatih Yüksel collected the data, analyzed the findings, and wrote the paper. Gülsen Tosun Tunç helped with the assistance of collecting data, supporting the data analysis, and helped with the writing of the paper.

Conflicts of Interest: The authors declare no conflict of interest.

\section{References}

1. Vicen, J.A.; Del Coso, J.; Millan, C.G.; Salinero, J.J.; Abian, P. Analysis of dehydration and strength in elite badminton players. PLoS ONE 2012, 7, e37821.

2. Tang, Z. Research on the effect of badminton game on improving physique in the perspective of the golden mean. Contemp. Sports Technol. 2012, 16, 502-506.

3. Available online: http:/ / www.bwfbadminton.org/page.aspx?id=15367 (accessed on 23 July 2017).

4. Cabello Manrique, D.; Gonzalez-Badillo, J.J. Analysis of the characteristics of competitive badminton. Br. J. Sports Med. 2003, 37, 62-66. [CrossRef] [PubMed] 
5. Faude, O.; Meyer, T.; Rosenberger, F.; Fries, M.; Huber, G.; Kindermann, W. Physiological characteristics of badminton match play. Eur. J. Appl. Physiol. 2007, 100, 479-485. [CrossRef] [PubMed]

6. Hughes, M.G.; Cosgrove, M. Badminton. In Sport and Exercise Physiology Testing Guidelines: The British Association of Sport and Exercise Science Guide; Winter, E.M., Jones, A.M., Davison, R.C., Bromley, P.D., Mercer, T.M., Eds.; Routledge: London, UK, 2007; pp. 214-219.

7. Aydoğmuş, M.; Arslanoğlu, E.; Şenel, Ö. Analysis of badminton competitions in 2012 London Olympics. Turk. J. Sport Exerc. 2014, 16, 55-60. [CrossRef]

8. Abian, P.; Castanedo, A.; Feng, X.Q.; Sampedro, J.; Abian-Vicen, J. Notational comparison of men's singles badminton matches between Olympic Games in Beijing and London. Int. J. Perform. Anal. Sport. 2014, 14, 42-53. [CrossRef]

9. Bankosz, Z.; Nawara, H.; Ociepa, M. Assessment of simple reaction time in badminton players. Trends Sports Sci. 2013, 20, 54-61.

10. Huynh, M. Training and Evaluating Champions: A Skills Acquisition Training Tool in Badminton; School of Mathematical and Geospatial Sciences College of Science, Health and Engineering, RMIT University: Melbourne, Australia, 2011.

11. Seth, B. Determination factors of badminton game performance. Int. J. Phys. Educ. Sports Health 2016, 3, $20-22$.

12. Revan, S.; Aydoğmuş, M.; Balcı, Ş.S.; Pepe, H.; Eroğlu, H. The evaluation of some physical and physiological characteristics of Turkish and foreign national badminton team players. J. Phys. Educ. Sports Sci. 2007, 1, 63-70.

13. Bhabhor, M.; Vidja, K.; Dubal, G.; Padalia, M.; Joshi, V. A comparative study of visual reaction time in badminton players and healthy controls. Indian J. Appl. Basic Med. Sci. 2013, 15, 76-82.

14. Bijanrajaeian; Mokhtari, P.; Mousavi, M.V. The Effect of visual practices on vision and movement performance of novice athletics in badminton sport. Bull. Environ. Pharmacol. Life Sci. 2014, 3, 114-118.

15. Aydoğmuş, M.; Revan, S.; Balcı, S..S.; Şenel, Ö. Physical profiles of the Turkish national badminton teams. J. Phys. Educ. Sports Sci. 2006, 8, 34-41.

16. Dube, S.P.; Mungal, S.U.; Kulkarni, M.B. Simple visual reaction time in badminton players: A comparatıve study. Nat. J. Physiol. Pharm. Pharmacol. 2015, 5, 176-179. [CrossRef]

17. Arslanoğlu, E.; Aydoğmuş, M.; Arslanoğlu, C.; Şenel, Ö. The relationship between reaction times and balance in elite badminton players. Nigde Univ. J. Phys. Educ. Sport Sci. 2010, 4, 131-136.

18. Günay, M.; Tamer, K.; Cicioğlu, İ. Spor Fizyolojisi ve Performans Ölçümü, 3rd ed.; Gazi Kitabevi: Ankara, Turkey, 2013; pp. 464-545.

19. Chow, T.H.; Chen, Y.S.; Lin, M.H. The characteristics of static plantar pressure and potential pain profiles in elite badminton players. J. Appl. Sci. Res. 2016, 12, 1-7.

20. Koley, S.; Goud, S. Correlations of handgrip strength with selected anthropometric variables in Indian junior and senior badminton players. Int. J. Recent Sci. Res. 2016, 7, 10351-10355.

21. Masu, Y.; Nagai, M. Characteristics of lower limb muscle activity during upper limb elevation in badminton players. J. Phys. Ther. Sci. 2016, 28, 2510-2514. [CrossRef] [PubMed]

22. Middleton, G.; Bishop, D.; Smith, C.; Gee, T. Effectiveness of a low-frequency sports-specific resistance and plyometric training programme: The case of an elite junior badminton player. Int. J. Coach. Sci. 2016, 10, $25-34$.

23. Ooi, C.H.; Tan, A.; Ahmad, A.; Kwong, K.W.; Sompong, R.; Mohd, G.; Khairul, A.; Liew, S.L.; Chai, W.J.; Thompson, M.W. Physiological characteristics of elite and sub-elite badminton players. J. Sports Sci. 2009, 27, 1591-1599. [CrossRef] [PubMed]

24. Ramos Alvarez, J.J.; Del Castillo, C.; Polo, P.; Ramon, R.; Bosch, M. Analysis of the physiological parameters of young Spanish badminton players. Exerc. Physiol. Sports Med. 2013, 11, 1-10.

25. World Health Organization. Obesity: Preventing and Managing the Global Epidemic: Report on a WHO Consultation (WHO Technical Report Series 894); World Health Organization: Geneva, Switzerland, 2000; p. 9.

26. Ağaoğlu, S.A.; Ergin, R. Analysis of agility, reaction time and balance variables at badminton players aged 9-14 years. Int. J. Sport. Exerc. Train. Sci. 2017, 3, 109-119. [CrossRef]

27. Çömük, N.; Erden, Z. Relationship between performance of triple jumping and reaction time and agility of ice skaters. Fizyoter Rehabil. 2010, 21, 75-80.

28. Gürsoy, R.; Akarsu, S.; Hazar, K. Examination of correlation among reaction time, strength, and flexibility of sedentary and athletes in different branches. Int. J. Hum. Sci. 2017, 14, 3282-3291. 
29. Ağılönü, A.; Kıratlı, G. The examination of the effects of 8-week plyometric training on some physical fitness parameters of women handball players aged between 12-16 years old. Int. J. Hum. Sci. 2015, 12, 1216-1228.

(C) 2018 by the authors. Licensee MDPI, Basel, Switzerland. This article is an open access article distributed under the terms and conditions of the Creative Commons Attribution (CC BY) license (http://creativecommons.org/licenses/by/4.0/). 